\title{
Study on the Framework Construction and Constructive Approaches of Smart Tourism Service System in Liaoning Province
}

\author{
Jianzhu Sun ${ }^{1, a}$ \\ ${ }^{1}$ Liaoning Institute of Science and Technology, Benxi City, Liaoning Province, China \\ a187119351@qq.com
}

Keywords: Smart Tourism; Service System; Approach.

\begin{abstract}
Constructing smart tourism service system is important to modern tourism industry. It is the key to break through in the progress of comprehensively promoting the development of smart tourism. It can provide guidance and reference for the systematic establishment of smart tourism in Liaoning province. On the basis of building the overall framework of smart tourism, this paper puts forward to approaches and countermeasures of constructing smart tourism.
\end{abstract}

\section{The Connotation of Smart Tourism Service System}

The definition of smart tourism service system. A system is an organic integrity with specific functions. It is composed of a number of things or ideas related with each other. Thus, "smart tourism service system" can be defined as the system of informationized and intellectual tourism products and services which are provided by the tourism related government sectors and authorities, together with other social organizations and economic organizations in the tourist destination. It appears when tourism industry develops to a certain moment. Its aim is to promote the further development of tourism industry, to meet the travel needs of tourists, as well as the comprehensive management and service demands of tourist agencies and authorities. Smart tourism system mainly includes sub-systems of travel and traffic information, tourist safety, tourism industry and administrative management, and enterprise management.

Service objects of smart tourism. To construct smart tourism service system, good services to three objects, tourists, tourism enterprises and tourism agencies, should be provided to improve the service quality of tourism, as well as the operation skills and management abilities of tourist agencies. These services also help to create good tourism environments and promote the rapid and healthy development of tourism economy.

Tourists. The six elements of tourism -- food, traveling, shelter, sight viewing, entertainment, and shopping -- can be integrated through the construction of smart tourism. Tourists can get information service of all destinations and whole process of travelling, such as the information inquiry, reasonable travel plans, booking and purchasing tickets, coupons and travel insurance before the travelling; intelligent navigation, travel guidance, intelligent guides and emergency rescue during the travelling; sharing travel notes, complaints and feedbacks, and settlement of insurance claims after the travelling. In this way, tourists can get the services of smart tourism.

Tourism enterprises. Through sharing tourism information, enterprise operation and local tourists can be combined together effectively. Then, marketing channels of enterprises could be expanded, their abilities of managing customers, employees and enterprise resources can be improved, personnel's working efficiency and service abilities could be improved, and the effective tourism e-commerce, including online marketing, online customer satisfaction surveys, tourists' behavior tracking and data statistics of tourists' demands, would be realized. Thence, enterprises can get more development opportunities.

Tourism authorities. Through the construction of smart tourism, tourism authorities can regulate and monitor the industry market, share and collaboratively operate tourism information and public service information with other tourism related units, enjoy the value of tourism destination marketing, and improve their detection and protection abilities towards tourists, tourism staffs and tourism 
ecological environment. Their marketing service ability and working efficiency of tourism business can also be promoted.

\section{Building the Framework of Smart Tourism Service System in Liaoning Province}

The overall framework of the smart tourism consists of application system in the front end, as well as support system and service supporting system in the back end. Inside the overall framework, units with different levels longitudinally interact; units with the same level horizontally interact. The content of interaction includes various data and services. Support system in the end back plays the roles of data bus and service bus. It schedules and coordinates various resources to ensure the efficient and orderly operation of internal resources. Application system in the front end services tourists, management departments and tourism enterprises. It meets the needs of all objects. The service supporting system ensures the orderly, healthy and stable development of smart tourism. Among them, the application system in the front end is the starting point and ultimate objective of smart tourism service system; it is the most important part in the construction of service system.

Services to tourists. Smart tourism inquiries. Tourism resources can be integrated by using techniques of Total Information Awareness and Cloud Computing in the area of Internet of Things. Tourists' inquires can change from "active query" to "passive choice". Massive real-time information updates in the system. Internet automatic screens information. With the help of "Integration of Three Networks" technique, travel consultation, tourists positioning and navigation, travel booking and purchasing can be combined together. Targeted travel planning services are provided according to tourists' different needs of group travel, independent travel, self-driving travel, business travel and other forms of travel. For tourists who want to choose group tour, travel agencies are recommend to them according to their travelling destinations and budgets, and according to travel agencies' scores which are marked through the comparison of their prices, service qualities and users' evaluations with other agencies.

Smart tourism booking and purchasing. Tourism industry is a special industry. The booking and purchasing of tourism products and services usually happens before or during the tourism consumption. It requires a single platform which can provide tourism booking, purchasing and consultation at the same time. The platform also needs to provide extensive and convenient channels for tourism booking and purchasing. Online booking of travel planning, tickets and hotel rooms, and purchasing of souvenirs and special local products, can be realized through intelligent terminals. Through combining with industries like smart bank, visitors can spend their money on tourism products and services safely and conveniently.

Smart tourism reception. Smart tourism reception includes navigation, tour guides and shopping guides. GPS with intelligent navigation function can provide users with not only ordinary navigation services, but also real-time information -- such as information on traffic control, traffic accidents, traffic congestion, parking lots and parking spaces -- through the Internet push. With the aid of map engines, GPS can provide travelers with the best routes from their starting points to attractions, hotels, restaurants and stations. It can also be used to search information.

Smart tourism service system provides tourists with vast real-time information, which can be used to guide their tours. When the users enter the cities in Liaoning which are listed on the smart tourism system, what they all need to do is logging in the system. Then, they can get information on food, living, travelling, shopping and entertainment. The system also helps tourists to make best travel plans according to their residence time periods, travel destinations, tastes for food, budgets and other key information.

In scenic regions and travel destinations, visitors can use intelligent terminal equipments in their hands to obtain detailed descriptions of these scenic spots. The forms of descriptions include text, pictures, video and 3D virtual reality.

Map module of smart tourism can be used to comprehensively learn and analyze travelling destinations in-depth at any time. It provides information of shops and evaluations. Online booking of travel planning, tickets and rooms, as well as the purchase of souvenirs and special local products, can 
be realized through intelligent terminals. Through combining with smart bank, quick pay can also be achieved.

After-sales service of smart tourism. With the help of tourism applications, sites, tourism forums and micro-blogs, smart tourism can achieve the interaction and communication between visitors with tourism enterprises, recipients, government departments and other visitors. Tourism complaints can also be settled timely on these platforms.

Services to tourism enterprises. Tourism enterprises include travel agencies, hotels and tourist attractions. In addition, during this era of e-commerce, tourism products distributors, such as Ctrip, e Long Travel and other travelling OTA, tourism electronic goods producers and suppliers, and products evaluation platforms also emerge. Smart tourism provides tourism enterprises with supply chains, resources management methods, online marketing and booking platforms, and other professional service systems. In this way, the intensive construction of informational enterprises can be realized to reduce business operating costs and technology barriers of information management. Through the establishment of scientific, rational and authorized evaluation standards for these enterprises, the information management system of objects' credits in tourism market can be improved. Meanwhile, electronic certification services should be standardized, electronic contract systems about the safety of tourism products should also be established to guarantee the fairness and security of market. Tourism electronic commerce system and financial system should be used to achieve the conveniently and safely use of applications with new payment methods.

Services to management departments. Through the construction of E-government affairs platform, the levels of office automation and administrative efficiency of management departments can be improved to reduce administrative costs; smooth channels for complaints and feedback of tourists can be provided; supervision for tourism markets can be strengthened; administrative news and information can be published timely; the qualities of tourism enterprises can be updated. The transparent supervision of tourism industry can be achieved to promote the overall improvement of service quality of this industry. In addition, the use of smart tourism applications in management sectors is also reflected in the construction of industry management system, as well as monitoring and forecasting systems.

\section{Approaches of Building Smart Tourism Service System}

Making overall planning and increasing government support. The constructing of smart tourism service system needs the participation of government departments, scenic spots supervisors, travel agencies, hotels and other related industries. It is a systematic project. A scientific and feasible plan is the prerequisite and basis for constructing smart tourism service. The plan needs to clearly put forward to development goals and contents from the perspective of action targets, provide definitions and constraints of the cohesion and combination of sub-systems and their service objects at all levels. The plan should be made according to the contents of four major systems of smart tourism system. At the same time, public security, transportation, commerce, health, quality inspection and medical security systems in the city also need to integrate into the plan organically, in order to give the full play of the guidance function of the plan. At the same time, guiding and incentive policies should be formulated and implemented to increase the support for smart tourism.

Focusing on visitors' experience, and promoting innovations of smart services. Tourists' behaviors mainly fall into three stages, before the travelling, during the travelling and after the travelling. During the travelling, most of tourists' eating, housing, sight viewing, shopping and entertainment requirements can be satisfied through Internet and mobile clients. This stage is the most important stage of smart tourism, and the essential stage which needs personalized service and humanity management. Smart tourism should exert positive influences and promote the innovation of management services.

Establishing smart tourism experience centers for tourists. Smart tourism experience centers should be different from traditional tourist centers. It needs to positively guide tourists to experience smart tourism and feel its functions. First of all, experience centers should focus on tourists' needs; integrate services of smart tourism which cover the whole stages of travelling. For example, when 
setting the electronic map and virtual tourism functions of a area, smart tourism also needs to improve the booking and payment functions of surrounding facilities which can provide catering and accommodation services. Secondly, the staffs of experience centers should provide visitors with smart tourism guide services, to expand the participation scope of travelers, and make more people enjoy the out fruit of smart tourism. Finally, experience center should enrich products of visitors' experience on smart tourism. By means of intelligent services, visitors can feel and experience smart tourism more vividly.

Building service system with smart phones as the core. Service system with smart phones as the core is a kind of personalized service which is chosen by tourists. Tours in tourist destinations are planned based on tourists' mobile phones. Mobile terminal will become the main carrier of smart tourism in the future.

First of all, supervisors of main scenic spots in Liaoning should build travelling applications with enough functions. These applications need to help travelers to access information of scenic spots more conveniently. They can also help travelers to make travel plans, book tickets, arrange accommodations and get new experiences. Secondly, these applications should be integrated with payment platforms in moving terminals. Currently, travelers cannot pay online in these applications. When improving these mobile terminals, tourists' payment habits should be considered. Payment platforms like WeChat, Alipay and mobile banking should be used to realize simple and convenient payments. Micropayments need to be realized without tapping passwords. Furthermore, QR code system should be developed. Setting up QR code in main attractions, visitors can get the scenic spot introductions in various forms such as voice, pictures and images through scanning the code. QR code can also be printed in the electronic tickets, and visitors can pay the ticket online through scanning the code. When entering the spots, tourists can enter to the parks after the staff scanning the electronic tickets in their mobile phones. Finally, maintaining and constructing public platforms like micro-blog and WeChat. Visitors can share their experiences during the travelling on these platforms; their complaints can also be posted in these platforms.

Providing people-oriented services and emotional caring. To achieve humanized, scientific management system, the traditional passive, afterwards management method should be changed to process, real-time management method. Information departments should cooperate with each other to share tourism data, and to build forecast and early warning mechanisms. Tourist data accumulation and analysis system can also be established to learn the needs, opinions and suggestions of tourists, and get information of tourism enterprises. In this way, scientific decision-making methods and management approaches can be achieved to effectively settle tourists' complaints and quality problems, and maintain the order of tourism market.

First of all, scientific and objective tourism planning and building system should be established, and infrastructure construction should be improved to provide good foundations for tourism management. For instance, the full coverage of WIFI in scenic spots is the foundation of information system management. Secondly, tourism government management platform at all levels should be established to achieve a high degree of integration of tourism information. Problem analysis helps to make intelligent decisions. For example, in the peak periods of holiday, total amount of travelers who enter a scenic spot can be controlled through total quantity control, online booking and peak-time excursion methods. Finally, a good environment of tourism supervision should be created. Visitors can access to more tourism management outcomes and evaluation channels. Then, the transparency of tourism management will be increased.

Strengthening publicity efforts and accelerating the transformation of functions. The effective application of smart tourism service relies on the promotion of smart tourism project. People's perceptions of smart tourism are weak, so the government and tourism enterprises should use public channels, such as official micro-blog, official website and television advertisement, to promote smart tourism project, and enhance people's perceptions of smart tourism. After all, the effective perceptions of "smart tourism service" of citizens are essential to the healthy development of smart tourism. Through appropriate marketing and promotion methods, peoples' awareness and perceptions 
of smart tourism can be enhanced. Then, the utilization level of smart tourism services can be improved, and the level of information of tourism in Liaoning cities can be promoted.

At the same time, the transformation of service functions of smart tourism should also be accelerated. The service objects of smart tourism should be changed from tourists, tourism enterprises and tourism management departments to the public; the service scopes should be extended from smart hotels, scenic spots, travel agencies and traffic to smart communities and education; the service functions should be changed from simple tourism function to the integration of leisure and culture functions.

Establishing talent banks and paying attention to personnel training. The construction of smart tourism service system is a long-time, systematic project with high technical requirements. It can be achieved though continuous development. The construction needs a large number of professional talents from various fields. Tourism management departments should cooperate with other tourism related enterprises to formulate relevant policies and take effective measures. Through a variety of ways and methods, talent banks, which are made up of particular occupational personnel with knowledge of tourism and advanced technology, should be established to effectively enhance the overall information and management levels of tourism industry. For example, relying on leading enterprises of the smart tourism industry, intellectual bases which can be used to do academic research, technology and product development and talent cultivation can be built to initiate the Think Tank project and attract high-tech tourism talents; high-end education platforms in universities and research institutes can be established to realize the unification of industry, university and institute, and to cultivate special talents of marketing, foreign language, tour guides and website editors in smart tourism industry.

\section{Acknowledgement}

Project fund: This paper is supported by Foundation for the Scientific Research Projects of Liaoning Provincial Department of Education in 2015 (Project No.: W2015227); it is also supported by Foundation for Liaoning Economic and Social Development Projects of Liaoning Provincial Federation Social Science Circles in 2016 (Project No.: 2017lslktyb-103).

\section{References}

[1] L. Liu, Empirical study on construction of information service system of smart city, Jilin University. 2012

[2] F. Liu, Shaping Smart Travel and Enriching Guests' Experience, 2nd E-Development Forum on China's Travel and Tourism Industry. 2010

[3] W.D. Jin, Smart tourism and construction of public tourist service system, J. Tourism Tribune. 02 (2012) 5-6. 